\title{
The drainage system performance in peat soil with permeability reduction
}

\author{
Andrey Nikitin ${ }^{1,}{ }^{*}$ and Olga Zaborskaya ${ }^{1}$ \\ ${ }^{1}$ Northern Federal University named after M.V. Lomonosov (NArFU), Severnaya Dvina Emb., 17, \\ Arkhangelsk, 163002, Russia
}

\begin{abstract}
Construction in waterlogged areas requires special design solutions and expensive site preparation works. Operating experience shows that the efficiency of drainage systems in peat soil decreases over time. This article describes factors to be taken into account when designing drainage systems in peat soil. It also summarizes the results of the laboratory surveys for peat and filling material permeability reduction over time. We used a laboratory box to study water permeability over time. In the experiment, we used poorly decomposed peat of natural structure and compacted peat. The study found that the water inflow into the drainage system decreased 1.5 to 1.7 times in the course of filtration. The greatest peat permeability reduction was recorded at the initial stage. The article demonstrates how the grain-size composition of sand used as backfilling affects its water permeability. In order to ensure normal operation of drainage systems in peat soil, one must consider the reduction of peat water permeability over time and clogging of sand filling when designing the said systems.
\end{abstract}

\section{Introduction}

Construction in waterlogged areas requires site preparation. Considering the engineering complexity and high cost of full peat reclamation, site preparation usually involves peat surcharging with sand and water level depression. Since peat settlement continues for decades, drains are installed on pile foundations. Piles are driven into solid mineral ground.

Figure 1 shows typical drain arrangement. Each support rests on two reinforced concrete piles with the cross-section of $300 \times 300 \mathrm{~mm}$. Pile spacing depends on the typical length of the support beam. Pile length is selected to make sure the pile is driven at least 2 $\mathrm{m}$ into the bearing layer. Reinforced concrete caps can be either pre-cast or cast-in-place. The drainage system is made of perforated asbestos-cement or plastic pipes 150 to $300 \mathrm{~mm}$ in diameter with wrapping filters and stone covers. Geotextile membranes are generally used for filter covers, and 5 to $40 \mathrm{~mm}$ grain size crushed stone is used for stone covers. Vertical wooden panels make sure the filling material remains stable as peat settles down in service.

\footnotetext{
* Corresponding author: nikitinavsafu@yandex.ru
} 


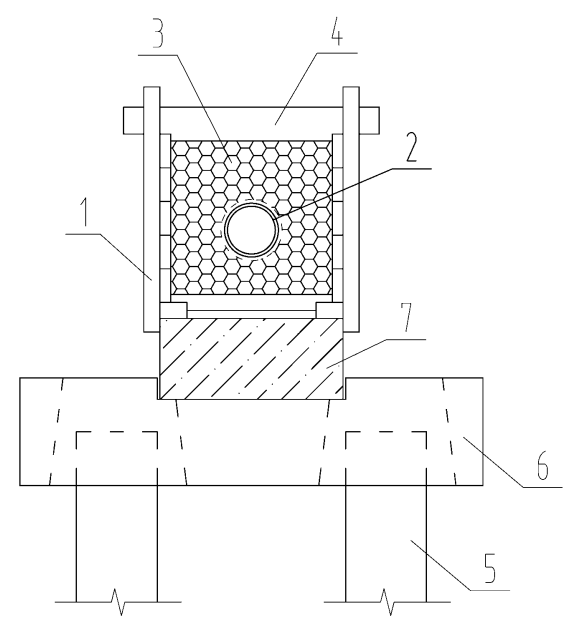

Fig. 1. Drain arrangement on reinforced concrete piles, where: 1 - wooden panel, 2 - drainpipe, 3 stone cover, 4 - tie member, 5 - reinforced concrete pile, 6 - reinforced concrete cap, 7 - reinforced concrete beams.

Inspection wells 1.0 or $1.5 \mathrm{~m}$ in diameter are installed at all drainpipe turning points and at straight runs every $50 \mathrm{~m}$. At the well sites, groups of three or four reinforced concrete piles with the cross-section of $300 \times 300 \mathrm{~mm}$ are provided. Cast-in-place reinforced concrete grillage is installed over the pile tops. The grillage supports well rings.

The experience of operating drainage systems in peaty soils has identified a considerable reduction of their water intake capacity and an increase of water level.

Depending on the drainpipe location relative to the peat top, drainage system malfunction can be caused by the following factors:

- Change of peat permeability when compacted under a supercharged layer.

- Peat clogging over time.

- Reduced water permeability of filling material and filter covers with mineral and organic particles carried over by groundwater.

Natural-state peat is water-permeable. Multiple surveys have proved that peat permeability significantly decreases after compaction [1-3].

Permeability factor at a given pressure is determined in accordance with formula [4]:

$$
\log \left(\frac{k}{k_{0}}\right)=\frac{\Delta e}{c_{k}},
$$

where $\Delta e$ is the porosity coefficient change,

$c_{k}$ is the coefficient accounting for the change in the permeability factor during compaction.

Numerical simulation uses $c_{k}$ value determined in the course of compression and filtration testing.

The effect of clogging described in the works of P.A. Drozd, K.E. Ivanov et al. contributes to reducing the peat permeability factor over time. This is related to the blocking of pores with fine particles contained in peat, as well as peat decomposition processes at temperatures above $15^{\circ} \mathrm{C}$. This effect occurs if the peat layer top is substantially above the drainage system. 


\section{Laboratory experiments}

To estimate peat permeability over time with the drain system in operation, we conducted a laboratory survey in a box measuring $0.4 \times 1.5 \times 1.0 \mathrm{~m}$ (Figure 2 ). The peat was poorly decomposed, with 16 to $18 \%$ content of particles below $0.25 \mathrm{~mm}$ in size. The drainage system included perforated pipes $110 \mathrm{~mm}$ in diameter, 5 to $20 \mathrm{~mm}$ grain size crushed stone cover, and fine sand backfilling. Non-woven geotextile with the density of $250 \mathrm{~g} / \mathrm{m}^{3}$ was used as filter wrapping the stone cover on the outside. During the experiment, continuous water inflow into the box was maintained. To prevent peat decomposition, the tests were carried out at the temperature of 5 to $10^{\circ} \mathrm{C}$.

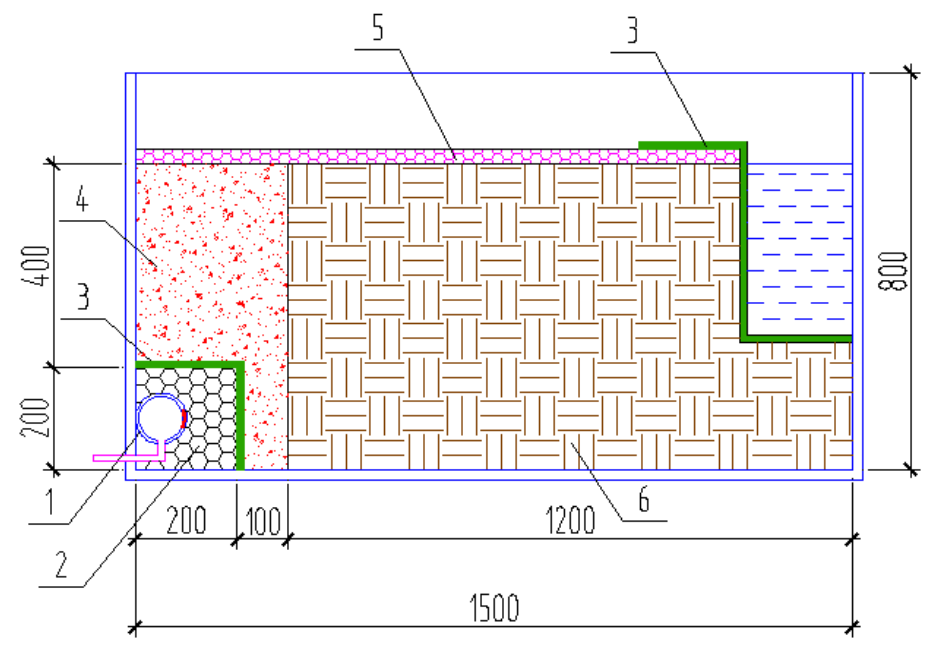

Fig. 2. Peat permeability survey unit configuration, where: 1 - PVC pipe $\varnothing 110 \mathrm{~mm}, 2$ - crushed stone 5-20 mm, 3 - geotextile, 4 - sand filling, 5 - crushed stone, 6 - peat.

In the experiment, we used both natural-state peat and surcharged peat. The pressure of $15 \mathrm{kPa}$ was applied to peat via a stamp during 20 days, then the load was removed and the stamp position was recorded. As water was seeping through peat, we measured its filtration rate. For example, Figure 3 shows water inflow change curve for natural-state peat.

The experiment has shown that water inflow into the drainage system for natural-state peat decreased 1.7 times, and for peat compacted by $15 \mathrm{kPa}$ pressure - decreased 1.5 times.

Filtration tube testing has shown that geotextile filter wrapped around drainpipes loses its permeability if the water being filtered has silty/clayey particles in it $[5,6,7,8,9]$. The survey has shown that geotextile filter wrapped around the drainpipes can start losing its permeability quite quickly where mineral particles and organic matter are present in the water. Placing geotextile filters over the external outline of the crushed stone cover improves the efficiency of the drainage system. 


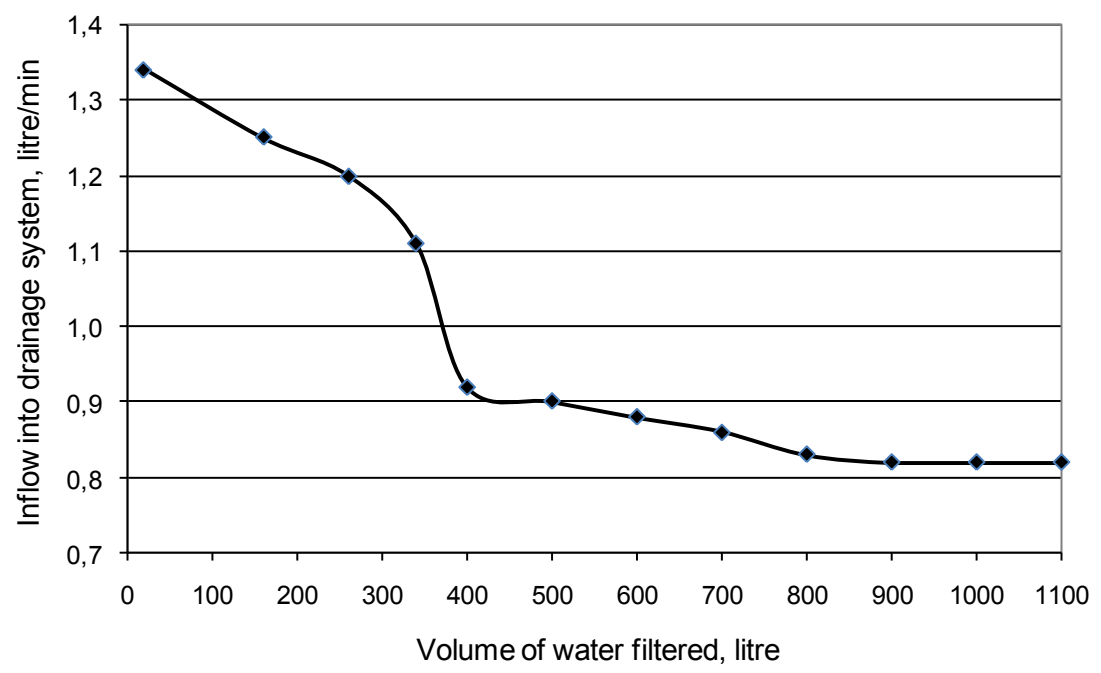

Fig. 3. Inflow change for unsurcharged peat.

To estimate the impact of filling sand grain-size composition on the drainage system performance, we carried out surveys using the instruments shown in Figure 4. We used fine and coarse sand for backfilling. Grain-size composition of sand is given in Table 1. For stone cover, we used crushed stone 5 to $20 \mathrm{~mm}$. Geotextile filter with the density of 250 $\mathrm{g} / \mathrm{m}^{3}$ was applied on top of the stone cover. To make the suspension, we added clayey particles obtained by crushing clay loam into water. The content of clayey particles in the suspension was $0.4 \mathrm{~g} / \mathrm{l}$. The test results are given in Figure 5.

Table 1. Grain-size composition of sand used as backfilling.

\begin{tabular}{|l|l|l|l|l|l|l|l|}
\hline \multirow{2}{*}{ Filling material } & \multicolumn{7}{|c|}{ Content of particles, \%, of size, $\mathrm{mm}$} \\
\cline { 2 - 8 } & $10-5$ & $5-2$ & $2-1$ & $1-0.5$ & $0.5-0.25$ & $0.25-0.10$ & $<0.1$ \\
\hline Fine sand & 0.00 & 0.04 & 0.62 & 2.06 & 39.25 & 57.79 & 0.23 \\
\hline Coarse sand & 2.27 & 4.42 & 15.58 & 29.22 & 25.61 & 22.74 & 0.16 \\
\hline
\end{tabular}
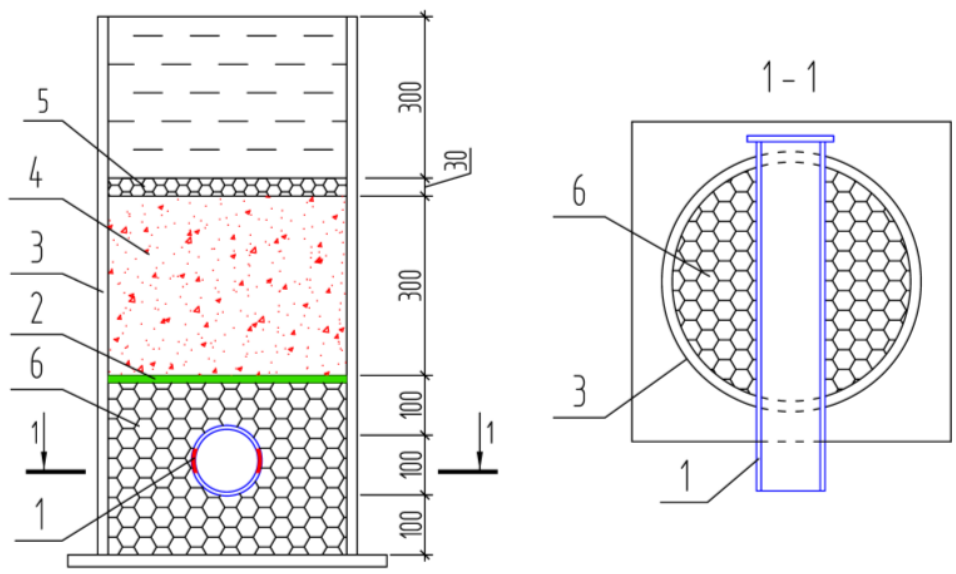

Fig. 4. Configuration of filling and filter cover survey unit, where: $1-\mathrm{PVC}$ pipe $\varnothing 110 \mathrm{~mm}, 2-$ geotextile, 3 - Ø500 $\mathrm{mm}$ vessel, 4 - sand filling, 5 - gravel, 6 - crushed stone 5 to $20 \mathrm{~mm}$. 


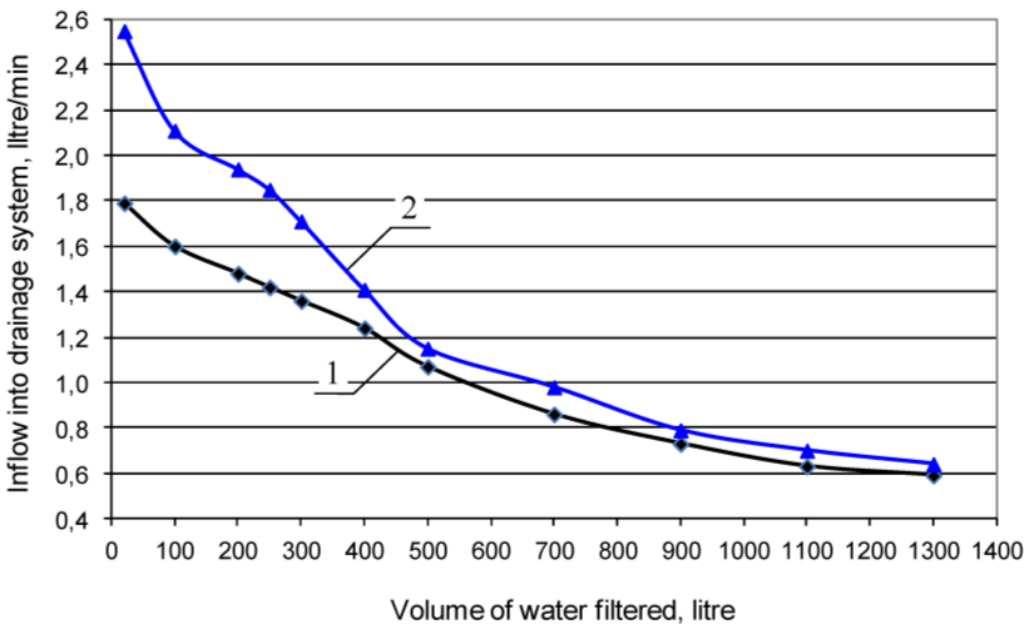

Fig. 5. Water inflow change for backfilling. 1 - fine sand, 2 - coarse sand.

As the suspension was seeping through, the inflow into the drainage system reduced 4 times for coarse sand filling and 3 times for fine sand filling. The water inflow reduction was caused by clogging of sand pores with fine particles contained in the suspension. This was proved by the results of particle size measurement at the drainpipe outlet. To determine the size of particles in the suspension, we used a laser analyser Lasentec D600E. Table 2 shows grain-size composition of the suspension at the drainage system outlet for fine sand backfilling. The greatest quantity of washed away particles is characteristic of coarse sand backfilling. By the end of the experiment, the quantity of silty/clayey particles being washed away decreased 10 to 40 times.

Table 2. Grain-size composition of particles at drainage system outlet for fine sand backfilling.

\begin{tabular}{|c|c|c|c|c|}
\hline \multirow{2}{*}{$\begin{array}{c}\text { The amount of } \\
\text { water filtered, } 1\end{array}$} & \multicolumn{4}{|c|}{$\begin{array}{c}\text { The quantity of particles of the given size } \\
\text { mm, per } 100 \mathrm{ml} \text { of water }\end{array}$} \\
\cline { 2 - 5 } & $0.15-0.30$ & $0.05-0.15$ & $0.01-0.05$ & $<0.01$ \\
\hline 0 & 1 & 13 & 104 & 203 \\
\hline 300 & 1 & 2 & 11 & 137 \\
\hline 700 & 1 & 2 & 11 & 6 \\
\hline 1300 & 1 & 2 & 10 & 5 \\
\hline
\end{tabular}

When the experiment was over, we took sand samples from the upper and lower layers of backfilling. Grain-size composition of backfilling is given in Table 3.

Table 3. Grain-size composition of sand backfilling.

\begin{tabular}{|c|c|c|c|c|c|c|c|}
\hline \multirow{2}{*}{$\begin{array}{c}\text { Backfilling } \\
\text { material }\end{array}$} & $10-5$ & $5-2$ & $2-1$ & $1-0.5$ & $0.5-0.25$ & $\begin{array}{c}0.25- \\
0.10\end{array}$ & $<0.1$ \\
\cline { 2 - 8 } & & & & & & & \\
\hline $\begin{array}{c}\text { Fine sand } \\
\text { - upper layer }\end{array}$ & 0 & 0.02 & 0.41 & 1.65 & 30.43 & 67.11 & 0.38 \\
- lower layer & 0 & 0.03 & 0.46 & 1.79 & 30.89 & 66.52 & 0.31 \\
\hline $\begin{array}{c}\text { Coarse sand } \\
\text { - upper layer }\end{array}$ & 2.82 & 3.34 & 16.61 & 30.43 & 25.24 & 21.31 & 0.25 \\
- lower layer & 2.67 & 4.04 & 15.87 & 30.74 & 25.47 & 21.00 & 0.21 \\
\hline
\end{tabular}

Table 3 shows that the amount of silty/clayey particles in the upper backfilling layer exceeds their content in the lower layer. Accumulation of particles in filling material can 
lead to a considerable reduction of water inflow into the drainage system and a decrease in drain efficiency.

\section{Analytical calculation and numerical simulation}

As an example, Figure 6 gives the results of the analytical calculation and numerical simulation of water depression for regular drainage (water table depth is given relative to the peat top). The thickness of the sphagnum peat layer is assumed to be $6 \mathrm{~m}$, the permeability factor of natural-structure peat $-4 \mathrm{~m} /$ day, infiltration $-310^{-3} \mathrm{~mm} /$ day. The peat is underlaid by impermeable clay soil. According to survey results, the filtering behaviour of sphagnum peat is assumed to be isotropic . A $1 \mathrm{~m}$ deep sand filling layer is provided over the peat surface. We assume the distance between the drainpipes of $120 \mathrm{~m}$, and pipe laying over the mineral bed.

The position of the depression curve for regular drainage can be determined analytically by formula [10]:

$$
y=\sqrt{h_{\max }^{2}-\frac{W}{k}\left(\frac{L}{2}-x\right)^{2}},
$$

Where $x, y$ are the respective coordinates of the depression curve (with the drain pipe axis assumed as the origin),

$W$ is the infiltration (permeation of atmospheric precipitation into the soil),

$k$ is the peat permeability factor (ground water velocity with a unity head gradient),

$L$ is the drain spacing.

$$
h_{\max }=\sqrt{\frac{W L^{2}}{4 k}+h^{2}},
$$

$h_{\max }$ is the water table in the middle between the drains,

$h$ is the water height in drainpipe.

Numerical simulation of water depression was performed using PLAXIS 2D software package. The software allows accounting for the change of peat permeability when compacted under a surcharge layer, as well as peat clogging over time. The value of factor $c_{k}$, which accounts for the change of permeability factor due to compaction, is assumed to be 3.8 in accordance with sphagnum peat survey results.

Water depression was simulated in PLAXIS in two stages:

- Stage 1: simulation of sand filling over peat layer.

- Stage 2: construction of a regular drainage system and determination of heavy filtration area.

- Stage 3: simulation of water depression taking into account peat clogging over time in the heavy filtration area. The permeability factor in the heavy filtration area was reduced 1.5 times according to the laboratory box survey results. 


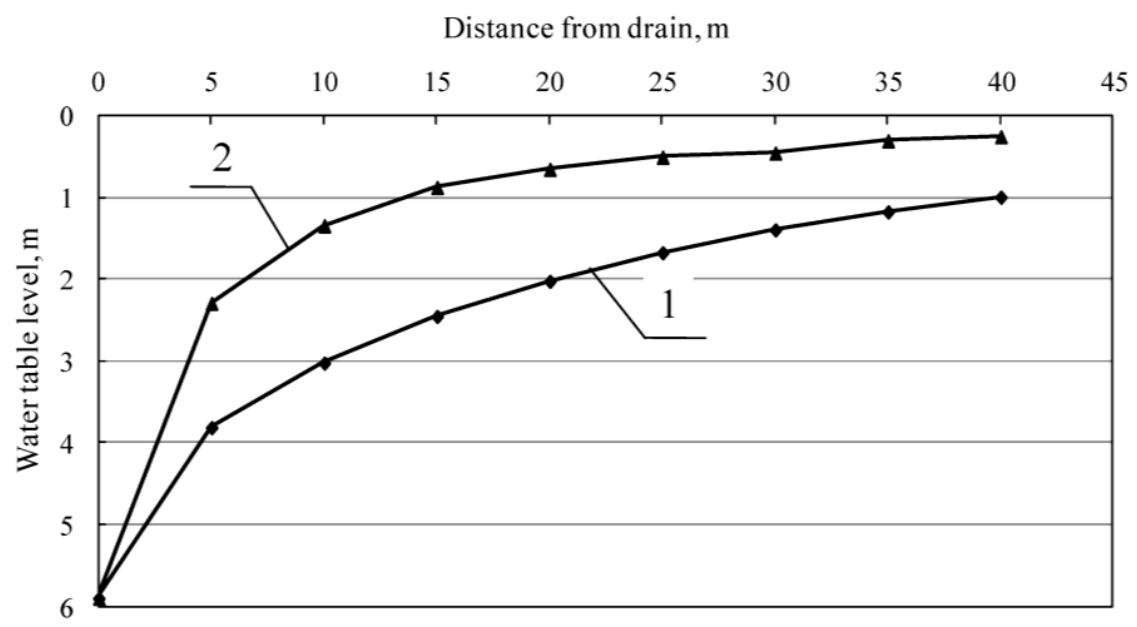

Fig. 6. Depression curves: 1 - analytical calculation, 2 - numerical simulation.

The water table level by analytical calculation differed considerably from that by numerical simulation in PLAXIS software. The deviation of water table reached $1.6 \mathrm{~m}$, which is due to the fact that software-based methods can account for filtration features of peat soils.

\section{Conclusion}

Based on the conducted survey, the following conclusions can be drawn:

- Drains in peaty soils must be designed with due account for peat permeability change caused by compaction under a surcharge layer, reduction of peat permeability over time, and clogging of sand backfilling.

- Backfilling must ensure adequate water intake capacity of drains.

- Using sand backfilling with a high content of silty/clayey particles can lead to clogging and reduced drain efficiency.

\section{References}

1. O. Zaborskaya, A. Nikitin, A. Nevzorov, MATEC Web Conf. 106 (2017)

2. A.L. Nevzorov, A.V. Nikitin, A.V. Zaruchevnyh, City on the swamp (2012)

3. N.P. Kovalenko, A.B. Hydyakov, V.S. Gorelyakov, Preliminary loading of a peat (1971)

4. Plaxis 3d manual (Netherlands 2010)

5. A.I. Mitrahovich, I.Ch. Kaz'miruk, Improvement 1(73), 54-67 (2015)

6. Ju.Ja. Tjumenev, M.Ju. Treshhalin, V.S. Mandron, Bulletin of the Association of Universities for tourism and service 3, 13-15 (2007)

7. Je.N. Shkutov, A.I. Mitrahovich, V.P. Ivanov, V.M. Makoed, V.A. Derevjanko, N.M. Avramenko, Improvement 1 (71), 22-30 (2014)

8. N.G. Pivovar, N.G. Bugaj, V.A. Rychko, Drainage with fiber filters (1980)

9. K.V. Svalova, Mining information-analytical Bulletin 6, 391-396 (2013)

10. P.V. Gordeyev. V.A. Shemelina. O.K. Shulyakova, Hydrogeology (1990) 